\title{
Techno-Economic Analysis of Transportation of Sequestered Carbon (IV) Oxide from Afam IV Power Plant
}

\author{
O. O. Ugwuanyi, ${ }^{1}$, U. C. Okonkwo, ${ }^{2}$, I. P. Okokpujie, ${ }^{3}$, C. A. Bolu, ${ }^{3}$ \\ ${ }^{1,2}$ Department of Mechanical Engineering, Nnamdi Azikiwe University. P.M.B 5025 Awka, Nigeria. \\ ${ }^{3}$ Department of Mechanical Engineering, Covenant University, Ota, Ogun State, Nigeria.
}

\begin{abstract}
:
Carbon capture and storage (CCS) has been recognized as one major technology that could sustain a greener environment. Because of the constant use of fuel for power generation, which releases $\mathrm{CO}_{2}$ that could be sequestered in geologic sites preventing their eventual release to the atmosphere. This study used Afam IV Gas Turbines in Nigeria as a case study and evaluated the emission of $\mathrm{CO}_{2}$ from the plants and the technoeconomic analysis of transporting captured $\mathrm{CO}_{2}$ from this power plant to Jones Creek (the propoFsed sequestration site in this study). The $\mathrm{CO}_{2}$ emission factor was determined from the daily energy generation from the gas consumption of the two turbines at the plant. Pipe Flo Professional 14 software was used for the pipeline design that was used for the transportation. The $\mathrm{CO}_{2}$ emissions from the two turbines were found to have a flow rate of $0.68 \mathrm{~kg} / \mathrm{s}$, requiring $4,416 \mathrm{~kW}$ and $61.402 \mathrm{~kW}$ of compressor power and pump power, respectively, each at $85 \%$ efficiency. This power requirement constitutes $3.44 \%$ of $130 \mathrm{MW}$ of the installed capacity of the two turbines at Afam IV. The capacity of Jones Creek was found to be $8.94 \times 10^{6} \mathrm{~m}^{3}$, and the pipeline cost for the transportation of $\mathrm{CO}_{2}$ was found to be 21.994Billion. The National Electricity Regulatory Commission (NERC) Multi-Year Tariff Order (MYTO) D3 billing rose to $600 \%$ during the construction period but dropped to $19 \%$ increment beyond the construction period as a result of the $\mathrm{CO}_{2}$ compression and transportation. It is recommended that the Federal Government of Nigeria should start to implement policies that would propel oil and gas companies in Nigeria to start considering CCS as an emission mitigation option in Nigeria.
\end{abstract}

Keywords: carbon capture and storage, multi-year tariff order, Sequestration, $\mathrm{CO}_{2}$, Pipeline

\section{INTRODUCTION}

Petroleum refining from upstream to downstream has been identified as one of the highest pollutant emissions [1-2]. Similarly, $\mathrm{CO}_{2}$ has been acknowledged as one of the most significant contributors to global warming due to its large volume in the environment. There are so many sources through which $\mathrm{CO}_{2}$ is being added to the atmosphere. In Nigeria, with 21 natural gas-fired power plants of different installed capacities, which are currently operating at different efficiencies because of reliability issues. This as a result of massive emissions from thermal power plants during operation. [3-6]

The continued emission of $\mathrm{CO}_{2}$ to the atmosphere as a result of energy requirements is leading to global warming, and Nigeria is not an exception [7-9]. The influence of global warming is being felt even in Nigeria, already resulting in desertification and flooding. Sambo et al. [10] reported that $84 \%$ of power generation in Nigeria comes from fossil fuel. Tsaurai [11] outlined changes in temperature and the atmospheric imbalance. The recurrent droughts, floods, and cyclones decline in some plant and animal populations - the spread of disease vectors, including malaria, freezing, and breaking of ice on rivers or lakes. Reducing food productions, an increase in death rate and threats are some of the observed effects of global warming in Nigeria. There have been earlier projections that developing countries will account for $81 \%$ of the projected increase in the world carbon emission between 1990 and 2010, and $76 \%$ between 1990 and 2020, (IEA, 2001)

Carbon Capture and Storage (CCS) is the technology that removes $\mathrm{CO}_{2}$ or carbon from flue gases for transportation and storage to geologic sites. Such as abandoned oil wells, unmineable coal seams, aquifers, or oceans. Carbon emission has been on the rise even with increasing carbon taxing; carbon capture and storage is proving to be the only option that would allow the continued use of fossil fuels such as coal, natural gas, and oils without a detrimental effect to the environment. CCS is suitable for carbon-intensive sectors such as power generation, cement production, oil mining, and steel production. Several writers have advocated for CCS as the hope for continued use of fossil fuel in an environmentally sustainable form. Statoil of Norway rather than pay hefty carbon emission fine, which was reduced from $\$ 200$ per ton of carbon (t C) to $\$ 140$ per $\mathrm{tC}$ in 2000 . Opted to be compressing and injecting the captured $\mathrm{CO}_{2}$ into a deep saltwater aquifer below the ocean floor since 1996, [12]. CCS is welcomed as the technology for the future, as the perspective of nonconventional sources of energy, such as solar, wind, and geothermal energy will not substitute the conventional fossil fuel in the immediate future. The CCS site map as of 2016 is shown in Fig. 1. Only one pilot project is located in South Africa and is operational while another 'in planning' is still situated in South Africa. 


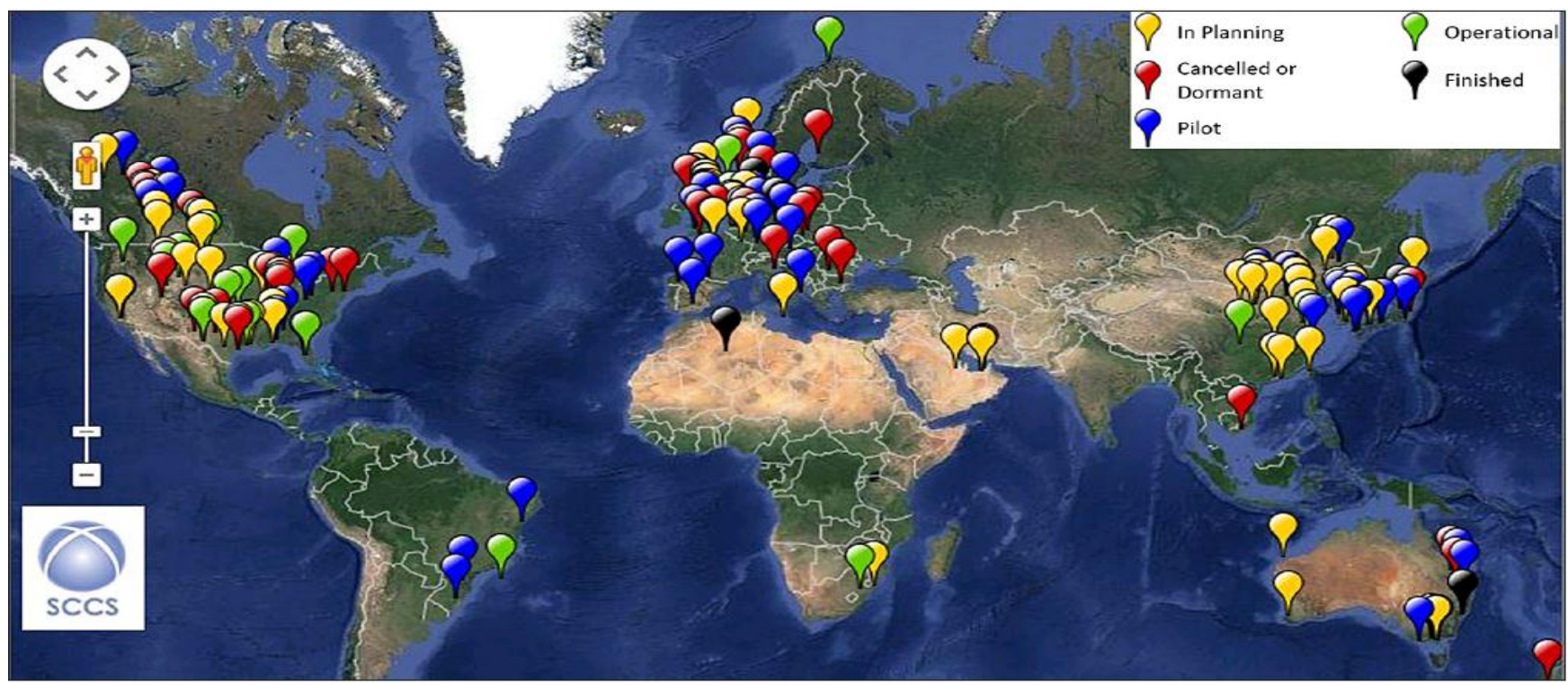

Fig. 1: CCS project map (source: [13], p. 25)

In addition, IEA estimated that an effort to reduce halve the global $\mathrm{CO}_{2}$ emission by half without $\mathrm{CCS}$ would increase the cost to more than $70 \%$ per year [14]

El-Suleiman et al. [15] presented the power requirements of compression of $\mathrm{CO}_{2}$ using Peng-Robinson's equation of state without actually computing the energy cost. Lazic et al. [16] did an extensive study of the cost of installation of a CCS system in the Humber region of the UK. Adopting no specific method but instead exploring data from different sources. Steem (nd) estimated that $75 \%$ of $\mathrm{CO}_{2}$ emissions come from fossil fuel combustion. A dense phase conditions, the liquid phase, and vapour pressure drop equation has been shown to give similar results for $\mathrm{CO}_{2}$ transportation through pipelines [16].

\section{EXPERIMENTAL}

This study aims at carrying out a techno-economic analysis of transportation of sequestered carbon(iv)oxide from Afam (IV) Power Plant by evaluating the effects of compression and transportation of capturable $\mathrm{CO}_{2}$ a component of CCS on NERC's MYTO.

Visits were made to the facilities of Afam Power (IV) Plant in Obigbo Local Government Area of Rivers State. The management of the plant provided the daily gas consumption data and daily energy generation between the period of $1 \mathrm{st}$ January 2012 and 31st December 2017. Two functional gas turbine units of the plant, gas turbine 17 (GT17) and gas turbine 18 (GT18), were evaluated. GT 17 and GT18 have installed a capacity of $65 \mathrm{MW}$ each. Neither of the turbine units was functional between the $30^{\text {th }}$ of April 2014 and $31^{\text {st }}$ of October 2017. The $\mathrm{CO}_{2}$ emissions of the turbines were not available at the plant, and thus, the emission factor was used to obtain the $\mathrm{CO}_{2}$ emissions from power generated. This study, while estimating the emission from thermal power plants, adopted the method developed by [17-18]. This method uses the emission factor to evaluate the flue gases of the power plants.

\section{II.I. Determination of fossil fuel power plant emission} To be able to analyze the emission of power plants, mathematical models have been developed to predict the radiation at different conditions.

This study used the emission factor in determining the $\mathrm{CO}_{2}$ emission [19].

$$
\mathrm{E}_{\mathrm{t}}=\sum\left(\mathrm{F}_{\mathrm{C}, \mathrm{t}} * \rho_{\mathrm{i} * \mathrm{H}_{\mathrm{u}} * \mathrm{EF}_{\mathrm{iCO}}}\right)
$$

Where $\mathrm{F}_{\mathrm{C}, \mathrm{t}}=$ Fuel consumption for the $\mathrm{t}$ period of time; $\rho_{\mathrm{i}}=$ fuel density at $15^{\circ} \mathrm{C}$ of fuel type $\mathrm{i}\left(\mathrm{kg} / \mathrm{m}^{3}\right)$

$\mathrm{Hu}=$ lower heating value of fuel (fuel oil or natural gas) $(\mathrm{MJ} / \mathrm{kg})$

$\mathrm{EF}_{\mathrm{iCO} 2}=$ national emission factor of $\mathrm{CO}_{2}$ of ith fuel $(\mathrm{g} / \mathrm{MJ})$

The national emission factor $\mathrm{EF}_{\mathrm{t}}$ is evaluated as:

$$
\mathrm{EF}_{\mathrm{t}}=\frac{\mathrm{E}_{\mathrm{t}}}{\mathrm{EG}_{\mathrm{t}}}
$$

Where $\mathrm{E}_{\mathrm{t}}$ is the total $\mathrm{CO}_{2}$ emission and $\mathrm{EG}_{\mathrm{t}}$ is the total electricity generation (MW)

Another approach to using emission factors to determine the emission of the power plant was adopted by and is presented here. The emission factor facilitates the estimation of emission from various sources of air pollution, including power generation plants, thermal power plants or cogeneration power plants that use fossil fuel. The emission factor is expressed in the unit of mass per unit of energy consumed or produced. The emission factor is expressed in $\mathrm{g} / \mathrm{GJ}$. For the determination of specified $\mathrm{CO}_{2}$ emission factors, the following general equations can be used:

$$
\mathrm{EF}_{\mathrm{CO}_{2}}=\frac{44}{12} \mathrm{c}_{\text {fuel }} * \varepsilon_{\mathrm{C}} * \frac{1}{\mathrm{Hu}} * 106\left(\frac{\mathrm{g}}{\mathrm{GJ}}\right)
$$

Where $\mathrm{C}_{\text {cfuel }}=$ carbon content of fuel (in mass of $\mathrm{C} / \mathrm{mass}$ of fuel) $(\mathrm{kg} / \mathrm{kg}), \varepsilon_{\mathrm{c}}=$ fraction of carbon oxidized (defined as the main part of carbon oxidized to $\mathrm{CO}_{2}$ ) 
The value of $\mathrm{CO}_{2}$ in the flue gas $=\mathrm{C}_{\mathrm{CO}_{2}} * \mathrm{E}_{\mathrm{fuel}}\left(\frac{\mathrm{g}}{\mathrm{m}^{3}}\right)$

The efficiency of the power plant can as well be used to determine the emission of the plant

$$
\begin{gathered}
\eta_{e}=\frac{E G_{t}}{F_{c, t}} \\
\eta_{t}=\frac{Q_{Y}}{F_{c, t}}
\end{gathered}
$$

Where $\eta_{\mathrm{e}}=$ electrical efficiency; $\eta_{\mathrm{t}}=$ thermal efficiency $\mathrm{EG}_{\mathrm{t}}=$ total electricity generation $(\mathrm{MW}) ; \mathrm{Q}_{\mathrm{y}}=$ useful heat produced by the plant
The emission factor is determined as follows:

$$
\mathrm{EF}_{\mathrm{CO}_{2}}=\frac{3.6 * 10^{-3}}{\eta_{\mathrm{t}}}\left(\frac{\mathrm{kg}}{\mathrm{MW}}\right)
$$

Improvement inefficiency of the power plant results in less emission for the same power output. The bigger the installed capacity, the more the emissions from the plant.

\section{II.II. Modeling of the Compressors and Pumps in Pipe Flo® Professional 14}

The transportation of the capturable $\mathrm{CO}_{2}$ via pipelines is analyzed in Pipe Flo Professional software, a pipeline analytical tool. The modeling is achieved by the use of the design points in Table 1.

Table 1: The $\mathrm{CO}_{2}$ and pipeline design parameters

\begin{tabular}{ll}
\hline Parameters & Values \\
\hline Pressure, $\mathrm{P}_{1}$ before compression & $1 \mathrm{bar}$ \\
Pressure, $\mathrm{P}_{2}$ after compression & $200 \mathrm{bar}$ \\
Temperature T & $35^{0} \mathrm{C}$ \\
Viscosity before compression & $0.00007344[\mathrm{~kg} / \mathrm{m}-\mathrm{s}]$ \\
Viscosity after compression & $0.00009174[\mathrm{~kg} / \mathrm{m}-\mathrm{s}]$ \\
Density before compression, $\rho$ & $1.725 \mathrm{~kg} / \mathrm{m}^{3}$ \\
Density after compression & $901.2 \mathrm{~kg} / \mathrm{m}^{3}$ \\
The hydraulic gradient between the turbine exhaust and capture point & $950 \mathrm{~m}$ \\
Distance between exhaust and capture point & $0.5 \mathrm{~km}$ \\
Hydraulic gradient between capture point and sequestration site & $950 \mathrm{~m}$ \\
Distance between capture point and sequestration site & $225 \mathrm{~km}$ \\
Compressor efficiency & 0.85 \\
Pump efficiency & 0.85 \\
\hline
\end{tabular}

The compression process was achieved using two-stage compression and the compression ratio obtained using equation (8)

$$
\mathrm{CR}=\left(\frac{\mathrm{P}_{\text {cut }- \text { off }}}{\mathrm{P}_{\text {initial }}}\right)^{\frac{1}{\mathrm{~N}_{\text {stage }}}}
$$

Where: $\mathrm{P}_{\text {cut-off }}=$ cut off pressure $(\mathrm{MPa}), \mathrm{P}_{\text {initial }}=$ initial pressure (MPa)

$\mathrm{N}_{\text {stage }}=$ the number of compression stages

The combination of two series-connected pumps achieves the use of pumps for the long-distance transportation of the compressed $\mathrm{CO} 2$ in condensed phase form. The pipe flow professional was able to compute the total heads of all the compressors and pumps. Thus saving them time and power consumed on manual iterations and computation of the DarcyWeisbach equation. The pipeline flow model for the compression and pumping stages are shown in Fig. 2 and Fig.
3. The two compressors and the stage one pump were installed at the point of capture. The stage two pump is a booster pump located midway between the point of capture and the sequestration site. The compression ratio calculated for the compression is 14.05 , and the pressure ratio for the pumping stages is 1.072 . The simulation software evaluates the total head of the compressors and the pumps, and this can now be applied in equations (9) and (10) to evaluate the power consumed by the compressors and the pumps.

$$
\begin{aligned}
\mathrm{P}_{\text {comp }} & =\frac{\dot{\mathrm{m}} * \mathrm{~g} * \mathrm{H}_{\mathrm{T}}}{\eta_{\mathrm{T}}} \\
\mathrm{P}_{\text {pump }} & =\frac{\dot{\mathrm{m}} * \mathrm{~g} * \mathrm{H}_{\mathrm{P}}}{\eta_{\mathrm{P}}}
\end{aligned}
$$

The flowsheet for the compression and pumping as set up in the Pipe Flo Professional is shown in Fig. 2 and Fig. 3, respectively. 


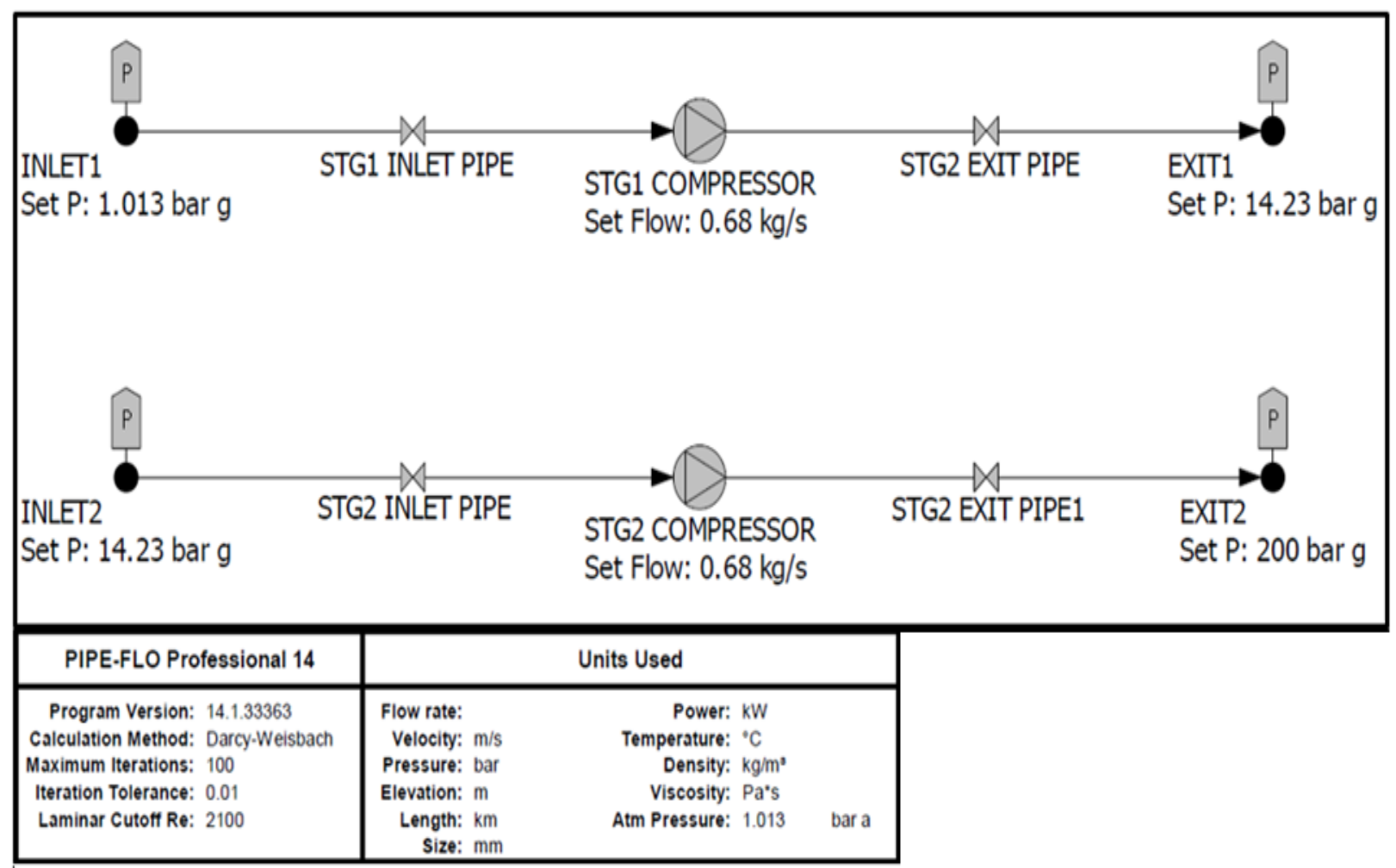

Fig. 2: The flowsheet for the compression stages of $\mathrm{CO}_{2}$.

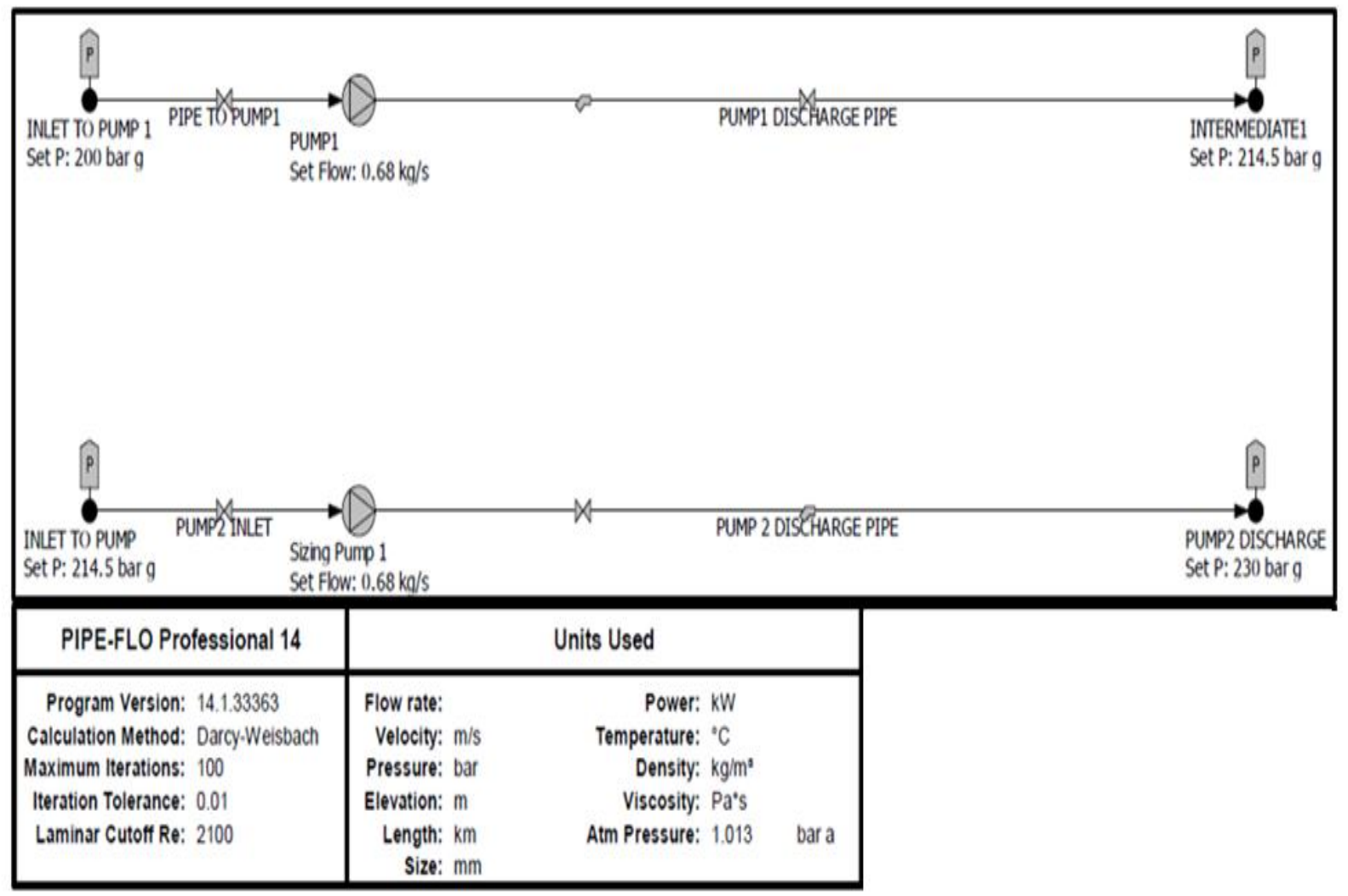

Fig. 3: The flowsheet for the pumping stages of $\mathrm{CO}_{2}$ in the condensed phase.

\section{RESULTS AND DISCUSSION}

The phase transformation of $\mathrm{CO}_{2}$ shows that it is easy to transport $\mathrm{CO}_{2}$ in a dense liquid phase if it is compressed to suitable temperature and pressure. It has been established that beyond the critical temperature and pressure, $\mathrm{CO}_{2}$ can be safely transported in the dense phase form. The processes of transportation are in two stages; stage one is the compression of $\mathrm{CO}_{2}$ to the appropriate temperature and pressure from the 
sequestration plant. The average flow rate of emitted $\mathrm{CO}_{2}$ from Afam IV turbines is $0.68 \mathrm{~kg} / \mathrm{s}$. This captured $\mathrm{CO}_{2}$ is compressed to a pressure of 200bar. After compression, a pump is used for long-distance transportation from the plant to the sequestration site. The parametric values for viscosity and density for the design of the pipeline in the Pipe Flo Professional 14 software were determined by deploying the EES software.

The DOE/NETL model was adopted in this work and is used to compute the pipeline cost for $\mathrm{CO}_{2}$ sequestration in Nigeria. To develop a costing model for the pipeline, there is a need for combination of the studies by the United States Department of Energy's and National Energy Technology Laboratory (NETL) on carbon dioxide transport with storage costs published in 2013 was adopted. $\mathrm{CO}_{2}$ transport costs are broken down into three categories: pipeline capital costs, related capital expenditures, and operation and maintenance $(\mathrm{O} \& \mathrm{M})$ costs. A regression analysis was used to generate the cost curves as a function of pipe diameter (in inches) and length (in miles). These costs are: (1) Pipeline Materials cost, (2) Direct Labour cost, (3) Miscellaneous Costs, and (4) Right-of-way acquisition cost [20], [21].

$\mathrm{CO}_{2}$ Emission from GT17 and GT18: There is instability in the amount of $\mathrm{CO}_{2}$ emitted for the periods considered, as depicted in Fig. 3. This instability is because of the erratic nature of energy generation. At periods of shut-downs, there were no emissions in the system at all. At periods when both GT17 and GT18 were operational, the amount of $\mathrm{CO}_{2}$ emissions becomes large comparably. In the pipeline, the design allowance is provided for the breakdown within the interconnections. Such that when one plant shuts down, other plants remain operational to keep the loop functional and profitable. The interconnectivity of all the power plants along the route keeps the pipeline functional at all the time though the allowance is created for breakdowns and maintenance. The accumulated monthly energy generated used to compute the monthly $\mathrm{CO}_{2}$ emission shown in Fig. 4.

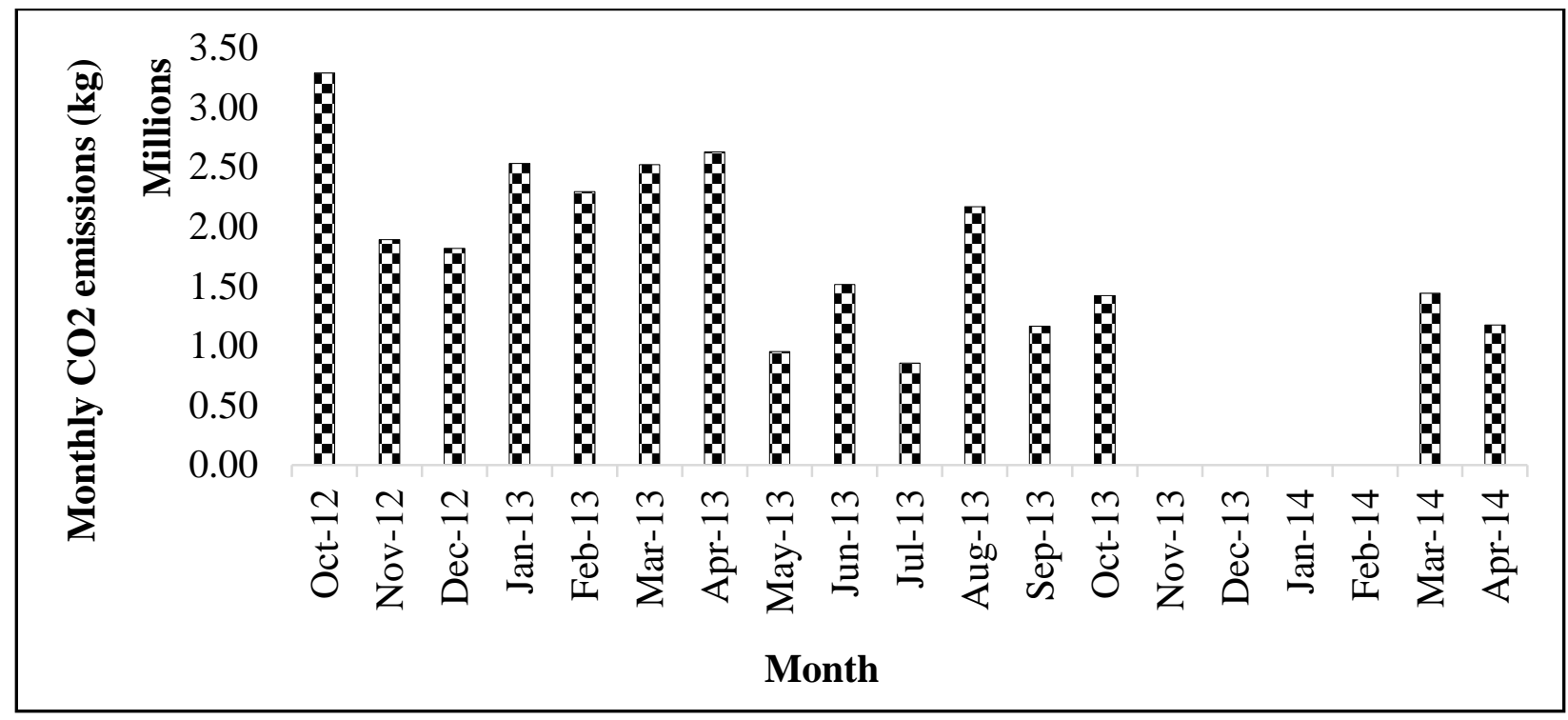

Fig. 4: $\mathrm{CO}_{2}$ emissions per months for GT17 and GT18

\section{III.I. The Analysis of the Cost Components of the Pipeline}

The pipeline cost is broken down into five categories, the material cost, the labour cost, the miscellaneous cost, right-ofway cost, $\mathrm{CO}_{2}$ surge tank cost, pipeline control system cost, and total O\&M cost. Labour cost is the major cost of pipeline gulping $69.57 \%$ of the total pipeline cost. Thus, it is right to conclude that one major constraint to the pipeline is more technical than material. The right of way cost is $7.83 \%$ of the total cost of the pipeline. The material cost and miscellaneous costs are significant components part of the pipeline cost, gulping $11.39 \%$ and $5.71 \%$ of the pipeline cost, respectively. The pipeline control system cost and $\mathrm{CO}_{2}$ surge tank cost are the least component cost of the pipeline cost with $\mathrm{CO}_{2}$ surge tank costing only $3.51 \%$ of the entire pipeline cost, and the pipeline control system costing a relatively insignificant $0.32 \%$. Total O\&M cost, which is an annual cost that is associated with the entire project life, is low compared with other costs. This favours the establishment of the pipeline system as the major cost are included in the fixed capital costs. This is presented in the chart of Fig. 5. These costs are dependent on the prevailing inflation rate and interest rate. The overall pipeline cost at an exchange rate of $\$ 1$ to N310 is Twenty-One Billion, Nine Hundred and Ninety-Four Million, Seven Hundred and Twenty Thousand, Three Hundred, and Sixty Billion Naira. ( 21,994,720,360). 


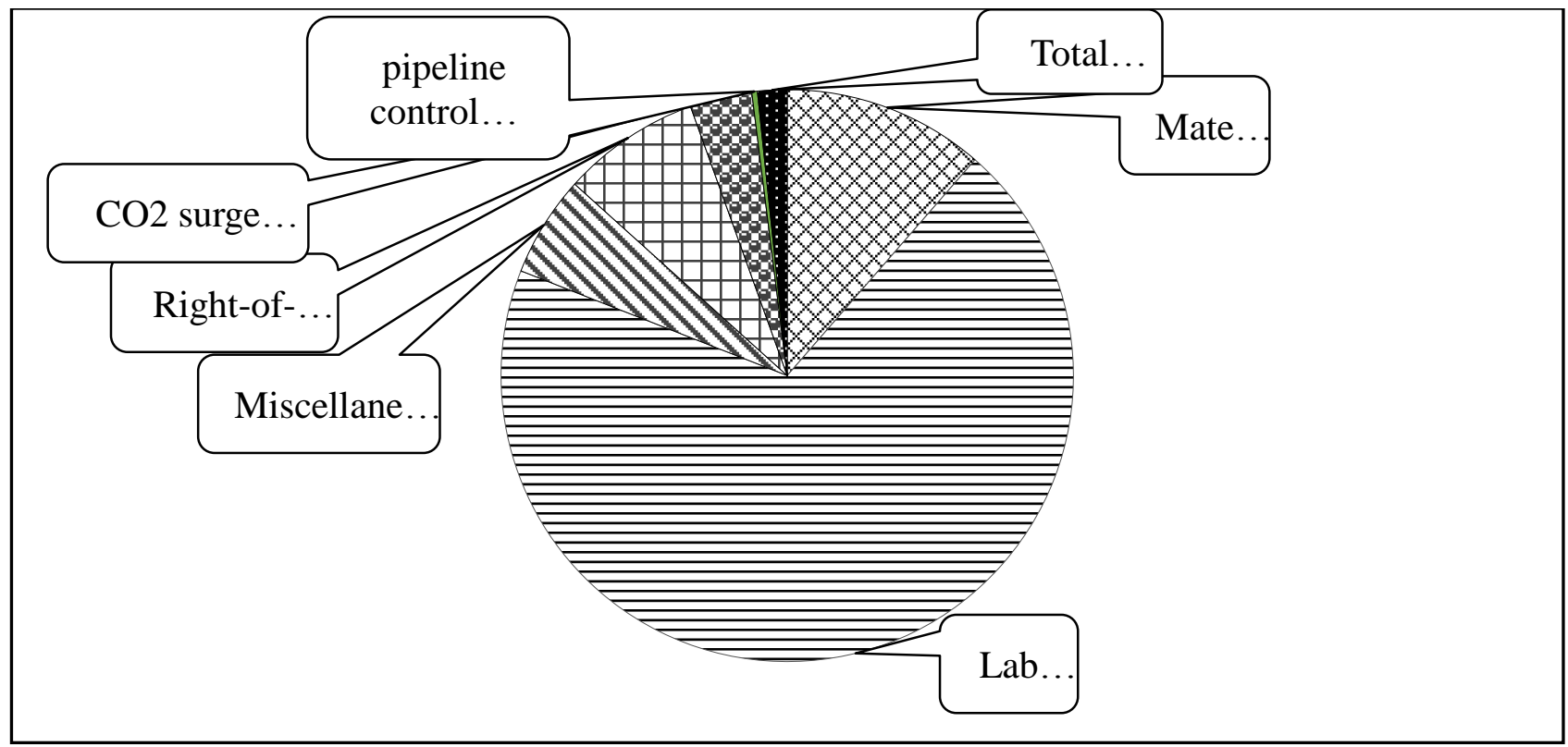

Fig. 5: Total $\mathrm{CO}_{2}$ pipeline component costs

Energy Cost Analysis: The energy cost of compression and pumping the captured $\mathrm{CO}_{2}$ was analyzed by using the power requirement of the compressors and pumps. To determine the yearly cost of running these pumps, the average energy cost for all the distribution companies for the years under consideration were used. The cost of pumping is minimal compared to the compression cost despite the distance that the pumped fluid will flow through. This is expected as less amount of energy is required to pump the same amount of fluid than to compress the same amount of liquid. This is presented in Fig. 6, where we observed the variations in the cost of energy based on the NERC's MYTO for each year. The initial rise and subsequent fall in the price of the energy is occasioned by an equally rising and falling MYTO of NERC. Thus with improvement in power supply and subsequent fall in energy charges, the amount required for the operation of captured $\mathrm{CO}_{2}$ pipelines will fall. The major cost is in the compression, as pumping is a small fraction of the cost of compression.

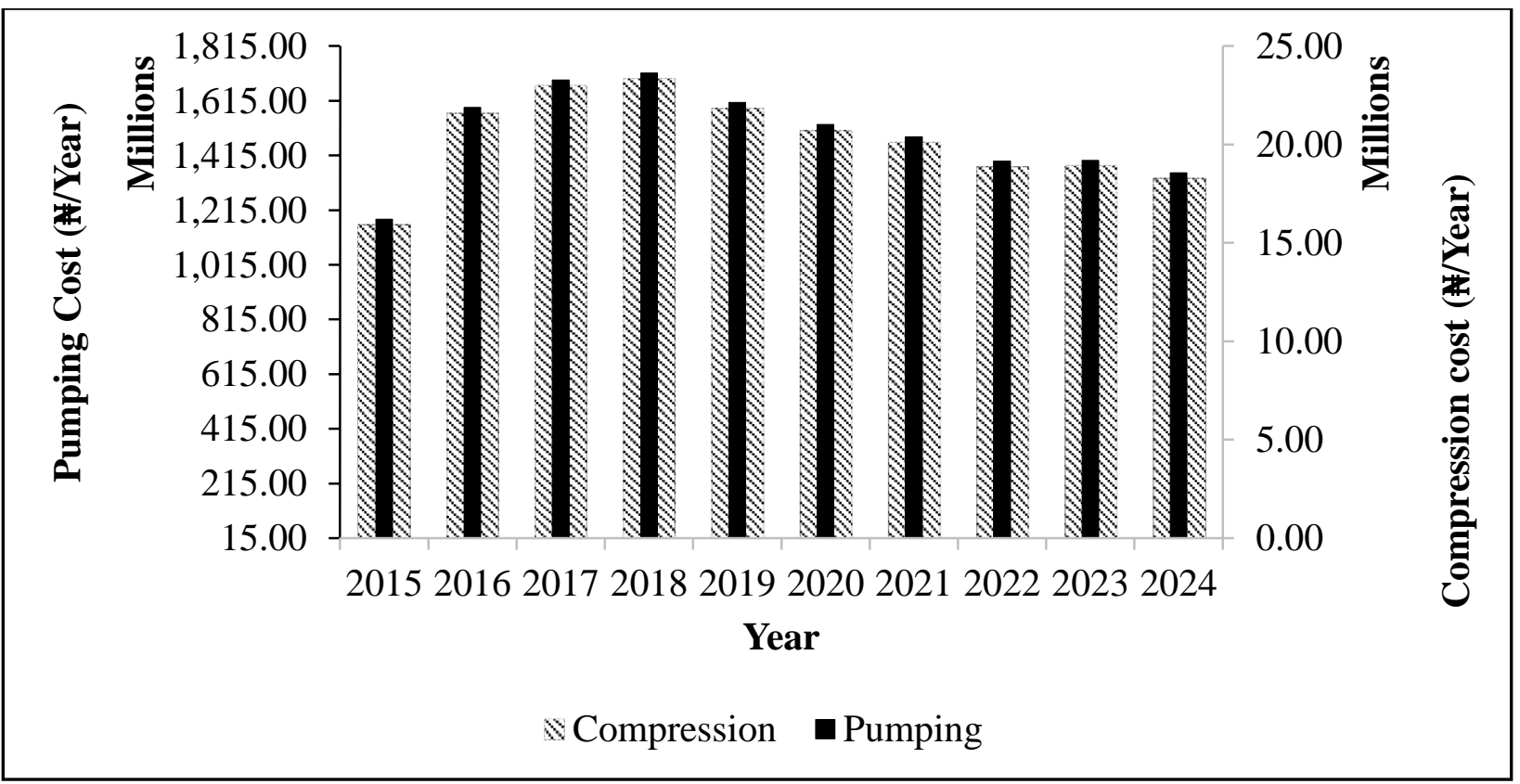

Fig. 6: The compression and pumping costs of $\mathrm{CO}_{2}$ for the years under consideration. 
The total cost is now summed up by adding the compression cost and the pipeline cost. The total cost is summed up into capital cost; include the pipeline material cost, labour cost, miscellaneous cost, right-of-way cost, $\mathrm{CO}_{2}$ surge tank cost, and pipeline control system,

O\&M cost (which provides for energy cost)

Energy costs and O\&M costs are annual payments that are affected by policy changes and inflation. Thus inflation and currency devaluation are accounted for as a percentage of the total cost. The capital cost is spread for five years, which is assumed to be the period of construction. An annual interest rate of $10 \%$ is compounded on the capital cost for the period of development. Then the yearly charge of $10 \%$ on operation and maintenance cost is charged on the O\&M cost for the years preceding the construction period, while a $5 \%$ inflation rate is assumed. We observe that the cost within the first five years is very high because of the cost of construction which has been factored into the construction cost. Beyond 2021, the price drops to a significantly lower value owing to the completion of construction. The cost associated with the pipeline is now the O\&M costs, as shown in Fig. 7.

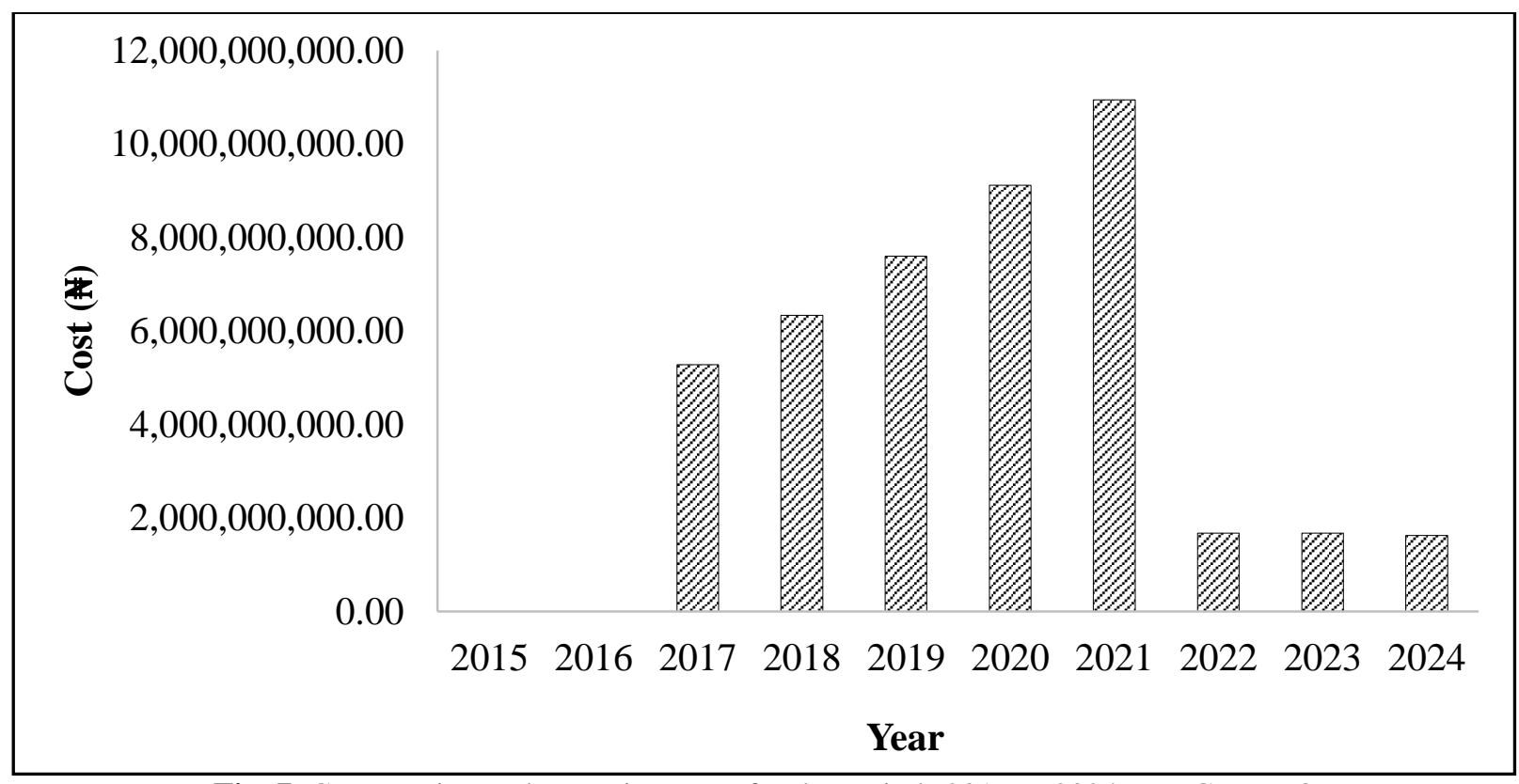

Fig. 7: Construction and operation costs for the periods 2016 to 2024 NERC MYTO

\section{III.II. The Impact of $\mathrm{CO}_{2}$ Compression and} Transportation on NERC's MYTO

The NERC's MYTO rises significantly above $600 \%$ for the first five years, and this covers the period of construction of the $\mathrm{CO}_{2}$ pipeline. In the subsequent years, the cost of energy for the consumer of electricity drops significantly to $19 \%$ of the pre-CCS years. This $19 \%$ increment in the price of power as a result of $\mathrm{CO}_{2}$ compression and transportation is very significant because the cost of capture and sequestration has not been included in the cost. But with efficient operation of the power plant and services at high capacity factor, this cost will significantly fall. This scenario is presented in Fig. 8.
The cost of energy with capture is compared with the cost of energy without capture and is presented in Fig. 9. From the figure, we see a wide margin between the cost of energy with the capture and the cost of energy without capture. This is highly pronounced in the first five years which is a result of the cost associated with the construction of the plant. In the following years, where the price is limited to the cost of operation and maintenance of the pipeline, there is a significant reduction in the cost of electricity. This significant reduction is still higher than the price of energy without capture. 


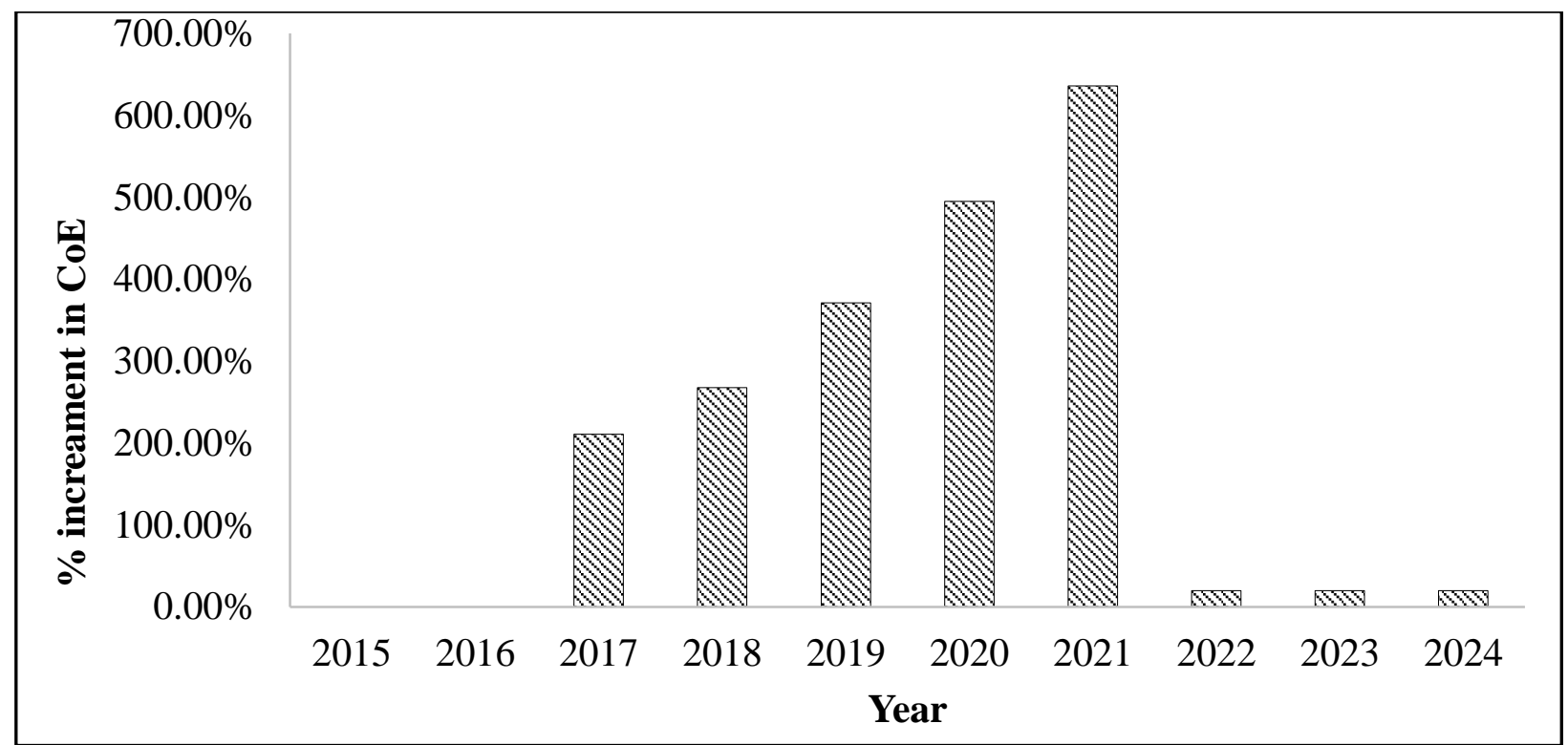

Fig. 8: Percentage increment in the cost of electricity attributable to $\mathrm{CO}_{2}$ transportation

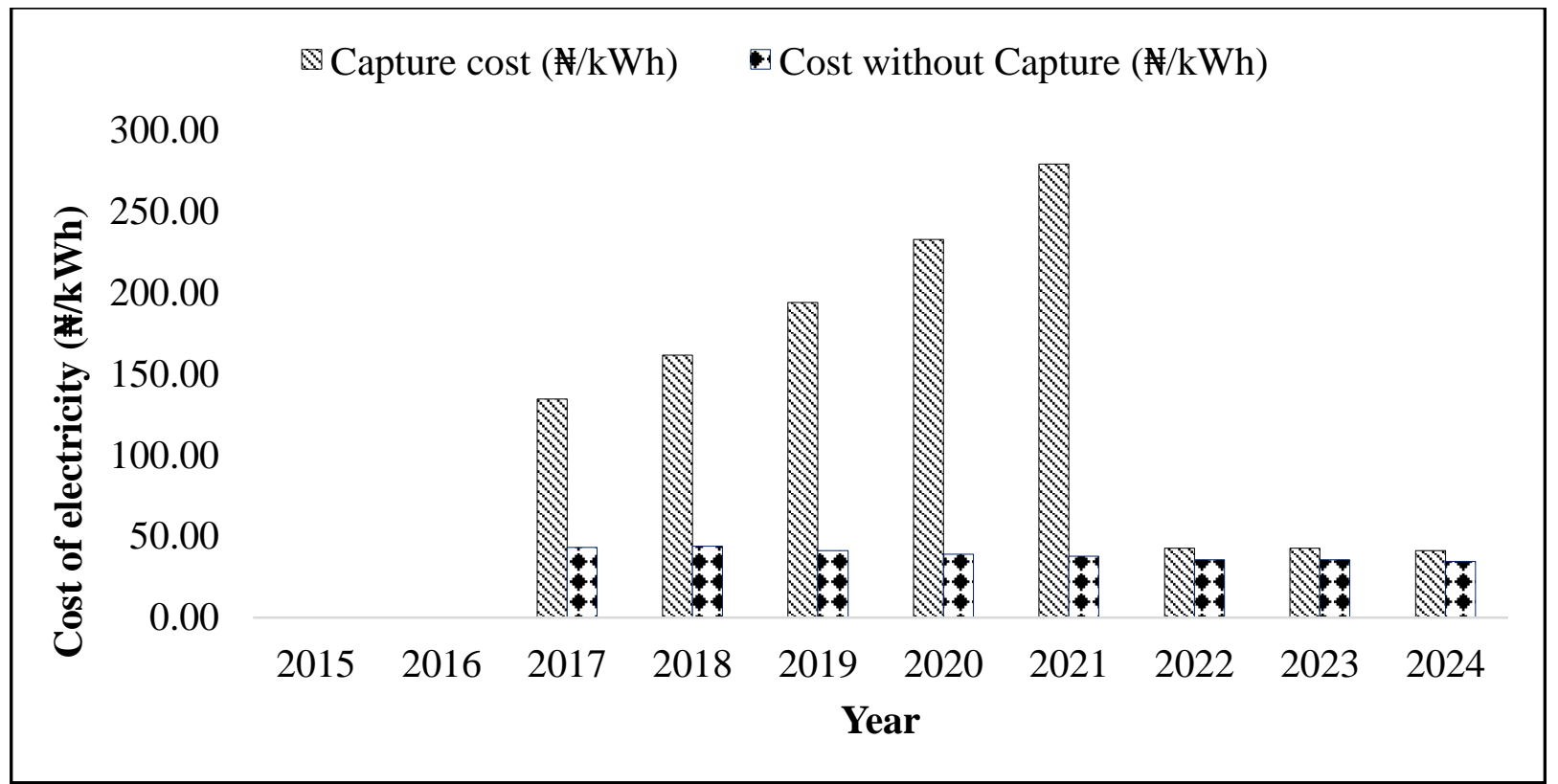

Fig. 9: The influence of $\mathrm{CO}_{2}$ compression and transportation on energy cost.

\section{CONCLUSION}

This study carried out a comprehensive investigation of the techno-economic analysis of transportation of sequestered $\mathrm{CO}_{2}$ from Afam IV plants to Jones Creek. With CCS, the incremental cost of energy associated with capturing, compressing, and transporting sequestered $\mathrm{CO}_{2}$ though very significant but with improvement in the mode of operation of the plants and retrofitting as many plants as possible will improve the capture rate and lower the energy cost. The policymakers should give the possibility of deploying CCS for the continued use of fossil fuels in power generation in Nigeria. Nigeria is yet to invest significantly in energy diversification. For a country seeking ways to mitigate against global warming while continuing to deploy fossil-fueled power plants for power generation. The development of a comprehensive CCS implementation plan is of great importance.

\section{ACKNOWLEDGMENTS}

The authors appreciate Covenant University management for their support towards the publication of this research work.

\section{REFERENCES}

1. Okonkwo UC, Ijioma IN, Onwuamaeze IP. Pollutants emissions of filling stations and their impact on the air quality. International Journal of Engineering. 2015 Jun 1;28(6):949-55.

2. Okokpujie IP, Okonkwo UC, Fayomi OS, Dirisu GB. Data on physicochemical properties of borehole water and surface water treated using reverse osmosis [RO] and ultra-violet [UV] radiation water treatment techniques. Chemical Data Collections. 2019 Apr 1; 20:100207.

3. Atikpakpa A, Okafor CE, Ugo O. Failure and reliability evaluation of turbines used in Nigerian thermal plant. J. 
Sci. Technol. Environ. Inform. 2016 Nov 14;4(01):28092.

4. Okafor CE, Atikpakpa A. Availability assessment of steam and gas turbine units of a thermal power station using Markovian approach. Archives of Current Research International. 2016;6(4):1-7.

5. Ogbe PO, Anosike NB, Okonkwo UC. Exergoeconomic Evaluation of Transcorp Power Plant Ughelli. International Research Journal of Engineering and Technology. 2016;3(11):36-44.

6. Okonkwo UC, Orji IN, Onwuamaeze I. Environmental Impact Assessment of Petrol And Gas Filling Stations On Air Quality In Umuahia, Nigeria. Global Journal of Engineering Research. 2014;13(1):11-20.

7. Saracoglu BO, Ohunakin OS, Adelekan DS, Gill J, Atiba OE, Okokpujie IP, Atayero AA. A framework for selecting the location of very large photovoltaic solar power plants on a global/supergrid. Energy Reports. 2018 Nov 1; 4:586-602.

8. Osekhoghene DJ, Olayinka OS, Isaac FO, Princess OI. IGNITION TIME OF SELECTED CEILING MATERIALS AND ESCAPE TEMPERATURE TIME PREDICTION OF FIRE FIGHTER RESCUE MISSION. Journal of Chemical Technology \& Metallurgy. 2019 Jan 1;54(1).

9. Udoye NE, Okokpujie IP, Okeniyi JO, Dirisu JO, Ikpotokin I. Techno-Economic Evaluation of Coalfired Power Plant in South East Nigeria, a Review. International Journal of Mechanical Engineering and Technology. 2019 Sep 11;10(3).

10. Sambo AS, Garba B, Zarma IH, Gaji MM. Electricity generation and the present challenges in the Nigerian power sector. Journal of Energy and Power Engineering. 2012 Jul 1;6(7):1050-9.

11. Tsaurai K. Greenhouse Gas Emissions and Economic Growth in Africa: Does Financial Development Play any Moderating Role? International Journal of Energy Economics and Policy. 2018;8(6):267.
12. Newell R, Anderson S. Prospects for carbon capture and storage technologies. 2003 Jan 1.

13. Tcvetkov P, Cherepovitsyn A. Prospects of CCS projects implementation in Russia: Environmental protection and economic opportunities. Journal of Ecological Engineering. 2016;17(2).

14. Yelebe ZR, Samuel RJ. Benefits and Challenges of Implementing Carbon Capture and Sequestration Technology in Nigeria. 2015, 42-49.

15. El-Suleiman A, Anosike NB, Pilidis P. A preliminary assessment of the initial compression power requirement in $\mathrm{CO} 2$ pipeline "Carbon Capture and Storage (CCS) technologies.” Technologies. 2016 Jun;4(2):15.

16. Lazic T, Oko E, Wang M. Case study on $\mathrm{CO} 2$ transport pipeline network design for Humber region in the UK. Proceedings of the institution of mechanical engineers, part e: journal of process mechanical engineering. 2014 Aug;228(3):210-25.

17. Coman D, Leca A. Method for Emissions Calculation for Cogeneration Power Plant Using Emission Factors.2014; 76(1), pp. 297-310.

18. KOLÁŘ F, Fott P, Svitilova J. Emissions of carbon dioxide of gaseous fuels calculated from their composition. atmosphere. 2004; 1(2(124)), pp. 279-287.

19. Tamba, J. G., Koffi, F. D., Monkam, L., Ngoh, S. K. and Biobiongono, S. N. Carbon Dioxide Emissions from Thermal Power Plants in Cameroon: A Case Study in Dibamba Power Development Company. Low Carbon Economy Scientific Research. 2013; 4, 35-40.

20. National Energy Technological Laboratory. Quality Guidelines for Energy System Studies: Carbon Dioxide Transport and Storage Costs in NETL Studies. Retrieved from www.netl.doe.gov/research/energyanalysis/search-publications/vuedetails?id=1027 2013.

21. Fayomi OS, Okokpujie IP, Udo M. The role of research in attaining sustainable development goals. InIOP Conference Series: Materials Science and Engineering 2018 Sep (Vol. 413, No. 1, p. 012002). IOP Publishing. 